\title{
A viagem a Paris de artistas brasileiros no final do século XIX
}

\author{
Ana Paula Cavalcanti Simioni
}

N a montagem da Academia brasileira - batizada em 1826 com o nome de I mperial Academia de Belas Artes - , a viagem à Europa desempenhou, desdeo início, um papel estratégico: permitia que os aspirantes à carreira artística se defrontassem com as obras e os ensinamentos dos "grandes mestres". Esses funcionavam como modelos que deveriam guiar a produção dos mais jovens, lições a serem incorporadas. Foi durante a gestão de Félix Émile Taunay, em 1844, com a regulamentação do Prêmio de Viagem aos melhores al unos, quefinalmente se concretizou a meta de enviar alunos ao exterior.

A té 1855, Roma, vista como o berço do classicismo, constituía o principal destino dos estudantes. $M$ as, aos poucos, a capital italiana cedeu espaço para Paris, alçada à condição de metrópolecultural do século XIX. A cidade luz concentrava o mais notável conjunto de instituições artísticas de outrora, como o enciclopédico M useu do Louvre, a escola de formação de artistas acadêmicos mais reputada mundialmente - École des Beaux-Arts (EBA) - e o espaço por excelência de consagração dos artistas: 0 afamado Salon anual. Paralelamente a essas imponentes instituições, publicamente governadas, havia toda uma rede de ateliês de artistas e escolas particulares que orbitavam o sistema oficial.

Tamanha concentração de atrativos seduzia jovens aspirantes às carreiras artísticas dos quatro cantos do mundo, com percursos e motivações bastante diversas. Entre eles al guns não passavam de amadores endinheira- 
1. Journal del'Académie Julian, Paris, 1, ano 7, 1906.

2. Valenotar quealguns outros trabalhos já sublinharam a importância da AcadémieJulian na formação deartistas locais, em especial o de Jorge Coli (1997), que traz uma lista, ainda queincompleta, debrasileiros egressos da academia, eo deCaleb Fa ria Alves (2003), quea abordou ao analisar a trajetória do pintor $\mathrm{Be}$ nedito Calixto.

\section{A documentação} consultada foi: AJ 470, ÉlèvesÉ trangers (18781928); AJ52 299, Élè ves Étrangers; AJ 42 249-250, ÉlèvesÉtrangers, AlmeidaJr., Pedro Américo, Rodolpho Amoedo. dos em busca de refinamento cultural, vendo nas belas-artes um passatempo importante e estimulante; outros aproveitavam seus períodos de férias para receberem lições com mestres renomados e, em especial, havia aqueles que eram obrigados, por serem bolsistas da academia nacional, a estagiarem em instituições previamente escolhidas dentro de um rígido programa de estudos. Para esses, a Académie Julian era, na França, o primeiro endereço.

A escola inaugurada em 1867 por Rudolf Julian (1839-1907) - um antigo aluno de Léon C ogniet eAlexandre Cabanel, pouco notável por seus dotes como pintor - inicialmente restringia-se a uma pequena sala na Passage des Panoramas, situada em M ontmartre. Em 1880, ao lado daquele espaço, o diretor abriu um curso exclusivamente para mulheres, a princípio com poucas discípulas, não mais de quarenta. Em pouco tempo, porém, seu empreendimento se tornou um império: em 1885 a escola já possuía quatrocentas alunas e, quatro anos mais tarde, atingia a cifra de seiscentas. Em duas décadas o diretor inaugurara nove ateliês espalhados pela cidade de Paris, entre os quais cinco dirigidos aos alunos do sexo masculino e os demais às mulheres ${ }^{1}$.

No último quartel do século XIX, mais precisamente entre 1882 e 1922, contabilizou-se, segundo os documentos encontrados nos Archives $\mathrm{N}$ ationales e nos arquivos particulares do senhor $\mathrm{D}$ el $\mathrm{D}$ ebbio, a passagem de 75 homens e catorze mulheres brasileiros pela instituição (cf. Simioni, 2004) (consultar tabela ao final). A pesar do contingente significativo, essa escola tem sido menos estudada pelos interessados em história da arte brasileira do que a École des Beaux-Arts, sobre a qual recai, comumente, o foco de interesse dos estudos brasileiros sobre arte acadêmica². Porém foram poucos os artistas patrícios que, segundo a documentação encontrada, realizaram de fato estágios duradouros na prestigiosa instituição oficial: Almeida Júnior (em 1878), Pedro Américo de Figueiredo e M ello (em 1863), Rodolfo Amoedo (em 1899), Lucílio de Albuquerque (em 1910) e sua esposa, G eorgina de Albuquerque (em 1910), a única mulher compatriota a vencer as exigentes provas de ingresso no período estudado ${ }^{3}$. N esse sentido, parece-me que vale a pena recuperar o papel desempenhado pela academia de Julian na formação de toda uma geração de artistas nacionais que, entre as duas últimas décadas do século XIX e as duas primeiras do século XX, procuraram ali os modelos do que consideravam a "melhor" arte.

0 que, afinal, essa escola tinha a oferecer a seus alunos? 0 que fazia com que tantos jovens estrangeiros se expatriassem, pelo menos por al guns 
anos, e pagassem relativamente caro para freqüentar suas aulas? A meu ver são três as razões que determinaram o sucesso da instituição: primeiramente, cabe ressaltar que ali eram perpetrados os mesmos métodos de ensino empregados na École des Beaux-Arts, de sorte que a escola de Julian funcionava como uma espécie de "cursinho preparatório" para o ingresso na prestigiosa escola oficial. Além disso, ela ocupava uma posição privilegiada no campo acadêmico francês, na medida em que contava em seu corpo docente com mestres renomados, que detinham as posições dominantes nos salões; eles atuavam a um só tempo como professores e como júri e tendiam a favorecer seus próprios discípulos nas concorridas premiações. E, por fim, a academia foi pioneira no ensino e na profissionalização das artistas do sexo feminino de todo o mundo, tornando-se convidativa para um grande contingente de mulheres que desejavam se aprimorar como artistas e que não encontravam em seus paí ses de origem a possibilidade de fazêlo.

\section{A Académie Julian em meio ao sistema artístico francês}

0 concurso de admissão da École des Beaux-Arts, a partir do decreto de 1884, determinava o mesmo procedimento para franceses e estrangeiros. As provas de ingresso realizavam-se duas vezes ao ano, nos meses de março e agosto, e consistiam nas seguintes etapas: para os pintores, um desenho a partir do natural em uma das sessões e a partir de um gesso em outra, a serem executados em doze horas (exame considerado eliminatório); depois um desenho de anatomia (osteologia) executável nas loges em duas horas; um exame de perspectiva a ser feito nas galerias em quatro horas; um objeto em relevo com indicações de linhas em perspectiva; um fragmento de figura modelada a partir de um gesso, a ser feito em nove horas; um exercício de arquitetura elementar, feito ao longo de seis horas nas gal erias; um exame, escrito ou oral, sobre as noções gerais de história. Para os escultores mantinham-se as mesmas etapas, porém não haveria prova de perspectiva, a figura deveria ser modelada d'après nature em condições similares às dos pintores. A penas os artistas premiados com medaIha ou com o primeiro lugar nos concursos precedentes estariam dispensados das provas de admissão (cf. Grunchec, 1990, pp. 37-43). Como se percebe, vencer tais concursos pressupunha um conhecimento prévio de anatomia, um certo traquejo na língua francesa, conhecimentos da história do país e, principalmente, uma habilidade notável no desenho. 
Procurando enfrentar a concorrência, muitos alunos franceses e estrangeiros cursavam ateliês particulares, como os de Julian, onde aprendiam as técnicas de controle das linhas e das cores, além de se exercitarem cotidianamente na captação do modelo vivo. 0 conhecimento do corpo humano esua exata representação eram aspectos primordiais na formação de qual quer artista. Somente dominando-os o pintor seria apto a conceber telas que seguissem o cânon acadêmico, calcado em uma hierarquia dos gêneros que previa, no cume, a pintura de história e, na seqüência, o retrato, as pinturas de gênero, as paisagens e, por fim, as naturezas-mortas.

As pinturas de gênero histórico versavam sobre grandes temas, retirados das tradições greco-romanas, cristãs ou de episódios representativos mais recentes. Todavia, independentemente do assunto, a figuração supunha a representação de conteúdos real izados por grandes homens, os ditos heróis. Seguindo as regras do decorum, os temas el evados deveriam ser representados de acordo, isto é, fatos heróicos mereciam representações que os enobrecessem, por meio de corpos bem desenhados, idealmente belos e agradáveis ao olho.

Como já notou Friedlander,

[...] 0 H erói [...] não era apenas alguém que realizava grandes feitos ou proezas físicas e cuja força muscular e bel eza física causavam admiração. Ele era, antes de mais nada, al guém [...] cujo nobre corpo revista uma al ma resplandecente de virtude e cujas realizações poderiam servir de exemplo como um ideal a ser atingido (2001, p. 19).

Logo, um bom artista acadêmico deveria saber representá-lo à altura de seu valor moral e, para tanto, urgia dominar por completo a arte de captar e descrever o corpo humano, centro simbólico e iconográfico daquele tipo de arte. E, com efeito, grande parte da memória iconográfica dos alunos (tanto estrangeiros como brasileiros) constitui-se de desenhos a partir do modelo vivo. A exemplo da remessa da escultora Julieta de França, primeira artista brasileira a receber 0 importante prêmio de viagem, entre 1901 e 1906 (cf. Simioni, 2004).

Visando a engendrar habilidades que orientassem os jovens artistas nesse sentido, as instituições oficiais prescreviam um currículo que estipulava, para os primeiros anos, o desenho de ornatos, o desenho figurado e 0 desenho d'après l'antique, realizado a partir de estampas e estatuetas em gesso. Era somente após dominar por completo a ciência da linha e da 


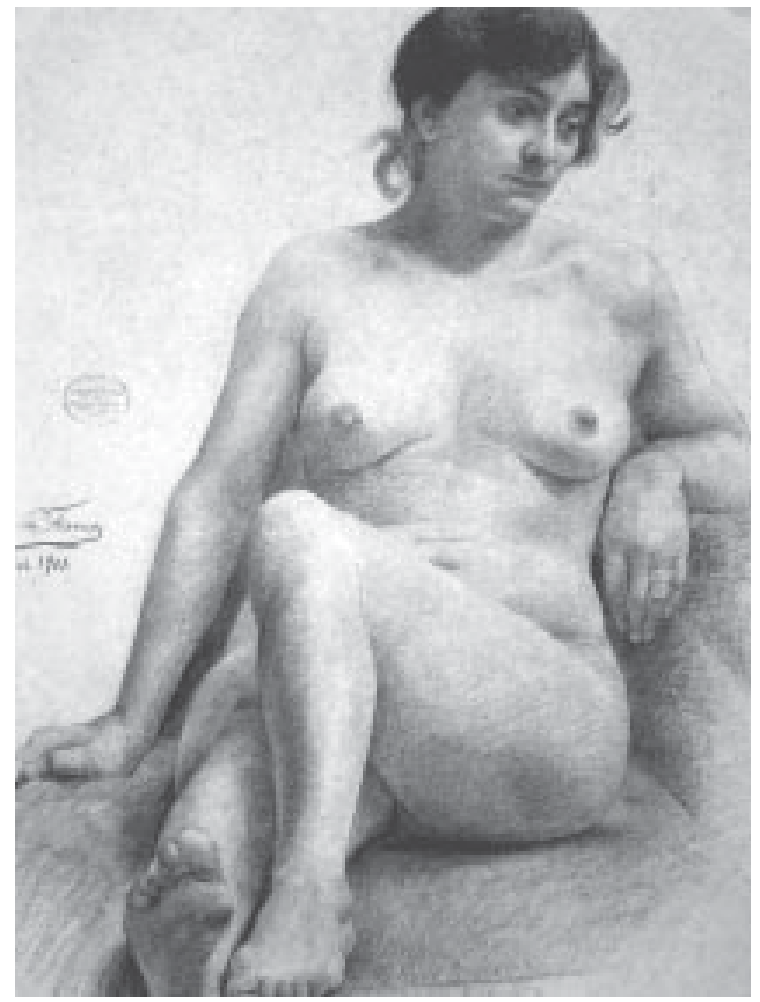

Julieta de França, Envio da pensionista,1901.

Com timbre da Académie Julian. Fonte: Museu Dom João VI.

proporção que o aprendiz teria acesso a um nível considerado avançado, como o do modelo vivo. $\mathrm{N}$ a Académie Julian, as etapas não eram tão rígidas, e alunos e alunas praticavam concomitantemente os diversos tipos de desenho. Certamente tal flexibilidade atraía uma clientela desejosa por informações que Ihe fossem úteis tanto para os exames oficiais como para o domínio das técnicas necessárias para a fatura de obras; 0 que ali se fornecia era um meio mais rápido para se alcançar tais objetivos.

$M$ as, uma vez formados e concursados na EBA, por que tantos alunos permaneciam na escola? $\mathrm{H}$ avia decerto outro motivo para que ela fosse tão procurada por aspirantes à carreira acadêmica. Um segundo ponto a ser demarcado no quetangeà centralidade da Académie Julian éo modo como ali, em virtude da contratação de um grupo seleto de professores, levou-sea cabo uma eficaz política de favorecimentos de seus discípulos. Ao contratar mestres distintos, que além do valor artístico ocupavam postos de prestígio nos salões, atuando como júri tanto de sel eção como de premiação, o diretor da escola assegurava as chances de sucesso para muitos de seus alunos. 
Essa clientela, que a cada dia parecia se multiplicar, ansiava pelas possibilidades de privilégio ali engendradas, atribuindo ao destaque obtido nas exposições o poder de determinar retornos gloriosos para seus países de origem, com novos clientes, mais dinheiro e, talvez ainda, fama.

Fizeram parte do quadro docente da Académie Julian: Jules Lefèbvre, membro da Academia em 1891 e presidente do júri de pintura na Société desArtistes Français; Tony Robert-Fleury, presidenteda Sociétédes Artistes Français e professor da EBA em 1905; W illiam Bouguereau, membro da Academia em 1876, professor da EBA em 1888 e presidente da Société des Artistes Français em 1902; Gabriel Ferrier, membro da Academia em 1896 e chefe de ateliê de pintura na EBA em 1904; Jean-Paul Laurens, professor da EBA em 1885 e membro da Academia em 1891; Gustave Boulanger, professor da EBA em 1883; $M$ arcel Baschet, eleito para a Academia em 1913; François Schommer, professor da EBA em 1910; e Raoul Verlet, professor da EBA em 1905, além de Paul G ervais e H enri Royer.

0 pertencimento à Academia implicava a possibilidade de eleger os júris dos Salons e de proclamar os vencedores do Prix de Rome. Certamente os professores contratados por Julian estavam mais propensos a aprovar seus próprios discípulos, que conheciam bem e que seguiam seus próprios preceitos, do que os desconhecidos. Até porque o sucesso dos seguidores poderia ser encarado como uma glorificação dos próprios mestres, o que resultava não apenas em reconhecimento, mas também em novos alunos e, portanto, mais recursos. Assim, o sistema propiciava uma espécie de circularidade por meio da qual professores e alunos se promoviam mutuamente, garantindo a reprodução das posições dominantes e dominadas. 0 fenômeno não passava desapercebido. U ma americana, Ellen $\mathrm{D}$ ay $\mathrm{H}$ ale, escreveu uma carta a uma amiga na qual narrava as artimanhas de Julian:

Caso sua amiga tenha qualquer inten ção de expor no Salão, este sistema está em uso de modo assombroso na escola de Julian. $0 \mathrm{~s}$ alunos que desejam expor mostram seus trabalhos a seus professores, os quais são mais severos no que diz respeito a lhes fornecer autorização. M as uma vez que a permissão seja acordada, os professores sustentam mais seus alunos pelos seus próprios votos, como membros do júri. I sso me parece injusto, mas é de fato muito razoável. O s expositores indicam sempre o nome de seus professores nos catálogos e, naturalmente, esses senhores conservam o direito de aceitar ou recusar 0 envio autorizado. Eles devem votar por eles e eu imagino que em geral os professores da Académie Julian votem de modo 
solidário pelos alunos que pertencem, sempre, a dois ou três entre eles (apud N oel, 1988, p. 151).

\section{0 espaço das mulheres}

Como foi dito até agora, para os artistas do sexo masculino o estágio na Académie Julian trazia habilidade técnica e bons contatos com mestres reputados pela instituição oficial. M as há um outro aspecto que trazia celebridade internacional à instituição nas décadas finais do século XIX: era uma das poucas escolas no mundo que ofereciam às artistas do sexo feminino uma formação equivalente àquela recebida pelos homens.

As mulheres que desejassem se tornar artistas não contavam com a possibilidade de acessar as mais notórias escolas públicas em seus próprios países. $\mathrm{N}$ a França, por exemplo, a École des Beaux-Arts só Ihes abriu as portas em 1897 e mesmo assim após muita insistência por partedegruposorganizados, como a U nion des Femmes Peintres et Sculpteurs. O utra prova do atraso na formação de mulheres foi sua exclusão daquele que era o prêmio máximo conferido aos alunos - o Prix de Voyage-, que só pôdeser por elas pleiteado em pleno século XX, em 1902, quando já não mais valia grande coisa (cf. Sauer, 1990). N os demais países a situação não era muito diferente. $\mathrm{N}$ a Alemanha, somente após 1914 as Academias de Berlim e D usseldorf, as mais afamadas, passaram a aceitar al unas, eno Brasil apenas em tempos republicanos se registraram inscrições femininas na Escola $\mathrm{N}$ acional de Belas Artes, mais precisamente em 1892 (cf. Simioni, 2004, pp. 64-87).

Várias historiadoras da arte feministas já apontaram como a principal causa de exclusão das mulheres do sistema acadêmico a impossibilidade de cursarem as aulas de modelo vivo. Ao longo do século XVIII, na França, a lei era clara: apenas quatro mulheres poderiam ingressar na instituição (enquanto o número de homens não tinha limites) e desde que fossem julgadas "excepcionais", em ordem expressa assinada por sua majestade 0 rei de França (cf. Sheriff, 1996). Com a Revolução Francesa, a situação de certo modo se agravou: elas foram formalmente excluídas da Academia, podendo entretanto participar das exposições de artee concorrer aos prêmios aí distribuídos (cf. Landes, 1988). Em grande parte, o fechamento institucional às mulheres derivou do papel central que o estudo do nu adquiriu na formação dos artistas, visto como uma prática indecente para o sexo "frágil".

As artistas eram alijadas do conhecimento do modelo vivo justamente no momento em que ele setornava tão essencial para a figuração dos heróis. 
Estes, por sua vez, tornaram-se fundamentais na composição das pinturas históricas, gênero mais alto da hierarquia. Assim, estar incapacitado de representar com perfeição o corpo humano implicava a exclusão do gênero mais elevado de acordo com os rígidos cânones acadêmicos. Por trás do rótulo "arte feminina" criado no século XIX, estava a crença de que as muIheres não eram capazes de realizarem-se nos gêneros superiores porque desconheciam as leis da grande arte. Linda N ochlin, em ensaio clássico, atribuiu a inexistência de grandes artistas mulheres a uma causa eminentemente social: a seu ver, a exclusão do sistema acadêmico, tendo como motivação a proibição de que assistissem às aulas de modelo vivo, cerceou suas possibilidades de conhecimento daquele elemento que era central na formação de um artista acadêmico (1971, p. 25).

Porém, ao longo dos 0 itocentos, na França, muitas artistas expuseram (cerca de $10 \%$ das obras enviadas aos salões era de mulheres e em algumas áreas, como nas aquarelas, 50\%) e muitas atingiram a notoriedade. Como? U ma transformação importante estava em curso: paral elamente às instituições oficiais despontavam escolas e cursos também endereçados ao público feminino. Essa dinâmica de ateliês privados foi paulatinamente eliminando o monopólio da formação que até então estava nas mãos da Academia (cf. Garb, 1998).

Ateliês particulares existiram desde o século XVIII, vários recebiam somente mulheres ou ao menos também mulheres: como o de AbilaideGuillard, o do próprio D avid, Abel Pujol (entre 1822-1855), Léon C ogniet (1834-1860), H enry Scheffer, o famoso ateliê de Charles Chaplin (18601870), 0 ateliê para escultoras de M me. Leon Bertaux (1873-?), o deM me. Trélat, aberto em 1874, que contava com G erôme, Leon Bonnat e Jules Lefèbvre como professores, recebendo muitos escandinavos. N esse contexto, é preciso entender a abertura de academias particulares no interior de um processo geral de proliferação de escolas particulares.

A Académie Julian destacou-se nesse processo. Pouco depois de sua fundação, já assinalava a existência de turmas mistas (desde 1873). A partir de 1880, o diretor se deu conta de que as turmas exclusivamente femininas teriam ainda mais sucesso em virtude da pudicícia de muitas alunas francesas, que não negavam o desconforto de coabitar o mesmo espaço com colegas homens. $\mathrm{N}$ as novas turmas as jovens encontraram uma formação equiparável à deles (cf. Feher, 1994). Ali podiam exercitar-se no modelo vivo, diariamente, por até oito horas seguidas, contando ainda com as lições fornecidas pel os grandes mestres que também lecionavam na 
EBA. O único senão éque deveriam estar dispostas a pagar caro por tantos privilégios: as mensalidades e as anuidades para mulheres custavam, geralmente, 0 dobro das masculinas4.

O utro aspecto positivo para o público feminino era a ênfasedada àformação de retratistas. Julian acreditava que, diferindo da pintura de história, que por suas proporções gigantescas e sua carga simbólica constituía um espaço quase que exclusivamente masculino, a pintura de retratos era um bom campo para as mulheres. 0 gênero estava então em alta, contando com diversos tipos de clientes nos vários países e, por suas dimensões pequenase ênfasenuma dimensão psicológica, parecia propício ao que outrora se acreditava ser uma típica sensibilidade feminina (cf. Weisberg, 2000). E, de fato, muitas americanas, como Cecília Beaux ou Elizabeth Gardner, ou a suíça Louise Breslau, tiraram partido disso: do duplo vínculo de retratistas e expositoras bem-sucedidas nos sal ões estabeleceram carreiras gloriosas em seus países de origem (cf. Weisberg, 2000; Lepdor, 2001).

Algumas brasileiras também buscaram, na Académie Julian, a formação que Ihes faltava em sua terra natal. Os dados sobre as mulheres são lacunares, pois cobrem apenas o intervalo de 1880 a 1905, e, mais grave ainda, encontram-se nas mãos de um proprietário particular. Ainda assim, o caderno referente às Élèves dames groupées par nations et par villes menciona as seguintes brasileiras: M me. Barbosa (em 1889), M me. Castillos (em 1889), M me. Capper (em 1896), M me. D eM esquita (1890), H ermina Palla (1893), M me. De Sistello (em 1892 e novamente em 1900), M me. Silva (em 1900), srta. M ariette Rezende (em 1900), srta. N egrão (em 1902), srta. H erré (em 1902), srta. Valim (1904). Além destas, o documento menciona artistas mais conhecidas, como as escultoras Julieta de França, que aportou no ano em que recebeu a bolsa conferida pela EN BA (1901), e N icolina Vaz, que se inscreveu na escola em 1904, bem como a pintora paulista srta. Bayeux (1903) e a caricaturista $N$ air de Teffé, também conhecida como Rian (em 1905) ${ }^{5}$.

No Brasil, as mulheres que queriam se formar como artistas se deparavam com 0 seguinte quadro: até 1881 , com a abertura das aulas para 0 sexo feminino no Liceu de Artes e 0 fícios, não havia instituição pública alguma apta a acolhêlas como discentes. E, mesmo nesse caso, o intuito era o de formar artesãos mais do que artistas. Já a Escola $\mathrm{N}$ acional de B elas Artes, a quem cabia o ensino das belas-artes, conforme já se viu, apenas em 1892 registrou a entrada de mulheres entre seus membros. $E$, embora não houvesse regulamento que as proibisse de freqüentar as aulas de nu, ainda
4.Em 1902, uma muIher despendia sessentafrancos por umajornada parcial deum mês e cem francos por uma integral, ao passo que um homem gastava respectivamente 25 ecinqüenta francos. Por uma anuidade de meio período elas gastavam quatrocentos francos, e setecentos pelaintegral, enquanto osalunosdesembolsavam duzentos e quatrocentos francos por formação equivalente.

5. A questão da documentação femininaépor si só um grande indício da pouca importância atribuída às mulheres pela história da arte 0 sr. D el D ebbio, ao comprar nosanos de 1980 a marca academie Julian, recebeu todaadocumentação disponível sobreos ateliês femininos, incluindo desenhos, livros de matrícula, pinturas etc. No mesmo ano, a documentação concernenteaos ateliêsmasculinos foi doada aos Archives $\mathrm{N}$ ationales de Paris, onde se encontra organizada eacessível ao público. Por isso, até às descobertas recentesempreendidaspor Weisberg eBecker (2000) e Feher (1994), pouco seconhe 
cia sobre as artistas que passaram pela escola. Os dadosquecito foram obtidos in loco, ou seja, o próprio sr. Del Debbio merecebeu egentilmentedisponibilizou o caderno sobre as brasileiras e as sul-americanas. Vale notar que, entre as vizinhas, o Brasil foi o país que enviou a maior delegação (15), seguido por Argentina(11), Colômbia (4), Chile (3), Bolívia (1) eGuatemala (1). Váriasartistasbrasilerras continuaram indo para a escola nos anos posteriores, como Georginade Albuquerque (1906), $\mathrm{H}$ elena P. da Silva O ha shi (nos anos de 1910), Tarsilado Amaral (1922), entreoutras. Essesdados, porém, não podem serve rificadosem livrosdema trícula, já que, segundo o sr. D el D ebbio, foram extraviados. assim tardiamente elas começaram a fazêlo, por motivos ligados aos costumes mais do que às leis (cf. Simioni, 2004). Nos primeiros anos de século XX, H elena Pereira da Silva $O$ hashi, uma brasileira que estagiou na Académie Julian, mesmo sendo filha de um artista (o pintor 0 scar Pereira da Silva), ainda se lembrava do choque que sentiu quando se deparou com o corpo humano:

Comecei o modelo vivo pela primeira vez na Academia Julian de Passages de Panoramas; quando vi o modelo nu, muito me intimidei. Eu ficava acanhada no meio das alunas, desenvoltas que riam e fal avam entre elas [...] (O hashi, 1969).

No geral, a Académie Julian ajudou consideravelmente as carreiras das brasileiras que aportaram no país. A exemplo da francesa Berthe Worms, que ao chegar a São Paulo nos primórdios do século XX, trazendo consigo aquela sólida formação recebida, setornou uma retratista concorrida, capaz de se sustentar com a própria profissão (cf. Simioni, 2004, pp. 224-235; Tarasantchi, 1996). 0 conhecimento do corpo humano revelou-se fecundo ainda para as caricaturas de $\mathrm{N}$ air de Teffé, com efeito a primeira mulher a se realizar nesse domínio; na pintura de Georgina de Albuquerque, cuja paleta impressionista acordava em justa medida com a maestria na representação dos modelos; e, finalmente, nas esculturas de Julieta de França e $\mathrm{N}$ icolina Vaz de Assis, para as quais a representação do corpo humano era matéria obrigatória para suas obras.

Assim, o estágio no exterior se mostrou interessante pelos seguintes motivos: pela aprendizagem técnica que habilitava tanto à pintura de história, gênero já decadente, quanto ao retrato, que era comercialmente vantajoso e gozava de prestígio junto aos colecionadores; pela importância simbólica que a passagem pela capital artística de então aportava à carreira, trazendo prestígio e outras marcas de distinção; e, finalmente, pela relação privilegiada que a escola possibilitava em relação aos júris dos salões e aos concursos de ingresso na EBA. Esses motivos fizeram da Académie Julian um importante centro propagador de determinados model os artísticos que se internacionalizaram, obedecendo a um ideal cosmopolita de arte. Procurar adequar-se a tais padrões era o desejo de todos os artistas que para lá seguiam, fossem homens ou mulheres. Isso traz um último ponto a ser discutido: o que esses artistas percebiam como moderno em suas viagens e o que traziam em seus retornos. 
Freqüentemente, a viagem desses artistas de orientação acadêmica foi descrita como insensível às novidades da cena artística parisiense ou incapaz de incorporá-las ${ }^{6}$. N ovidade, neste caso, aparece como sinônimo de vanguarda. Tal perspectiva historiográfica assenta-se em determinadas balizas, de orientação modernista, que foram responsáveis por introduzir fissuras específicas no campo artístico. 0 s impressionistas foram alçados à condição de "vanguarda" e, como tal, sujeitos das inovações que invadiram os finais do século XIX, sobretudo por seu antiacademismo; por outro lado, existiam aqueles outros, genericamente rotulados como "acadêmicos", que teriam sido apáticos às mudanças. Esses últimos, os "não modernos" por excelência (o que inclui os herdeiros de Julian), teriam permanecido acantonados nos espaços oficiais que agonizavam sem queeles se dessem conta. M as tal perspectiva necessita ser revista.

A crença de que o moderno implica, fundamentalmente, uma fatura do tipo impressionista estabeleceu-se como um primado analítico ao longo do século XX, resultado da ascensão de determinados grupos artísticos que, ao vencerem as rivalidades travadas com seus pares, impuseram como legítima a sua visão de mundo e a sua concepção de arte (cf. Bourdieu, 1989). Todavia, para muitos artistas latino-americanos aportados na França finissecular, a busca pela "modernização" das artes locais não passava, somente, pela incorporação absoluta dos legados impressionistas. As inovações formais eram ombreadas em importância por aquilo que identificavam como "temas modernos".

Laura M alosetti Costa, analisando o caso dos pintores argentinos, se pergunta se a adesão ao impressionismo é mesmo o melhor modo de se avaliar a sincronicidade almejada com a modernidade européia. Ao contrário, lhe parece que

[...] es posible problematizar ese estrecho margen donde radicaría lo "nuevo" en el arte de las últimas décadas del siglo iluminando zonas que exceden los límites de lo puramente formal, planteando la modernidad en el nivel de la calle, en términos de experiencia y autoconciencia (2001, p. 23).

Tanto brasileiros como argentinos se defrontavam com uma situação complexa: eram artistas periféricos com uma bagagem cosmopolita; oriundos de países cujos governos levavam adiante, com resultados desiguais,
6. Em especial, refirome à tipologia proposta por José C arlos Durand (1989) acerca da viagem dos pintores "caipiras" versus a dos pintores "modernos". Para o autor, os primeiroseram desprovidosde capital cultural esocial, por isso foram incapazes de perceber eincorporar as diversasfaces da "modernidade", ao passo que os segundos tinham as condições ne cessárias, o habitus, que Ihes possibilitou absorver e encarnar o que havia de maismoderno e, assim, realizar as rupturas modernistas em seus países de origem. 
processos de modernização (urbana, política e cultural) inspirados em modelos do além-mar, notadamente aqueles parisienses. Concordo com a autora quando diz que, para eles, se "modernizar" não significava apenas absorver aspectos "formais" da nova arte, mas também seu repertório te mático, aquela iconografia que viam como emblematicamente moderna e quelhes cobrava a difícil tarefa de ser traduzida para seus respectivos meios.

Assim, parece-me improvável que artistas que permaneceram por tantos anos em um espaço tão fervilhante como Paris fossem cegos para as novidades que assolavam suas próprias áreas. M ais provável é que incorporassem as mudanças mediante crivos particulares, os quais podem ser entendidos em dois sentidos: a) a partir da escola que cursaram e do modo como ela filtrava as inovações estéticas, e b) a partir dos seus próprios interesses particulares: esses "periféricos cosmopolitas" pretendiam construir uma nova arte que atendesse, ao mesmo tempo, às demandas locais e a um desejado universalismo.

\section{Diálogos artísticos}

7. A artista russa M arie Bashkirtseff foi um dos expoentesdaescola. Seus dotes eram admirados: além de boa pintora, provinha deuma nobre e rica família e era tida como uma mulher excepcionalmentebela. Foi aluna de Tony RobertFleury, o quelheajudou a ter obras aceitas nos salões oficiais. D eixou um longo diário, considerado documento valioso para se conhecer a sociabilidade, a educação eo cotidiano dasmulhe res artistas na Paris oitocentista. A edição por mim consultada dos Journals foi a publicada em 1925 pelaBibliothè que Charpentier.
D e certo modo, a Académie Julian foi responsável por uma espécie de amortecimento ou de filtragem das novidades artísticas. Ali, professores orientavam seus alunos conforme as regras acadêmicas, conferiam-Ihes as mesmas diretrizes, engendravam as mesmas habilidades, porém de modo mais rápido. $M$ antinha-se a crença de que o desenho deveria preponderar sobre a pintura pois ele era o testemunho da arte como um processo eminentemente intelectual, e não apenas manual. O s mestres da Académie Julian mantinham-se fiéis às longas rotinas acadêmicas e perpetuavam a crença no desenho como um processo intelectual central na formação artística, ao lado de uma extrema val orização da hierarquia dos gêneros, da composição acadêmica e, por fim, do próprio sistema acadêmico (cf. Goldstein, 1996, pp. 15-17).

Embora a pintura fosse considerada subordinada ao desenho, e as típicas regras da pintura de ateliê fossem valorizadas dentro da escola, isso não significava que o impressionismo fosse desconhecido e tampouco que tivesse sido intei ramente rejeitado. Pelos jornais da escola e pelos diários de uma de suas destacadas alunas, a pintora russa M arie Bashkirtseff (18581884), nota-se que, no período em que o maior número de brasileiros aportou na instituição, havia sim uma discreta abertura para as novidades impressionistas7. Um dos artistas mais admirados nos anos de 1880, co- 
nhecido pelo padrão queinaugurara nas obras de caval ete, foi Jules BastienLepage (1848-1884). Sua tela Les foins, exposta no Salão de 1877, o consagrou; ela parecia encarnar o desejado equilíbrio entre o que havia de melhor em cada uma das tradições, sendo percebido por seus contemporâneos como um mestre, um exemplo a ser seguido. Bashkirtseff dizia que ele "tudo reuniu" e, ao seu ver, era "o rei de todos, não apenas pela execução miraculosa, mas pela profundidade da intensidade dos sentimentos" (1925, p. 441).

Bastien-Lepage seguia os mesmos procedimentos realizados por aquele que foi o mais notável pintor da III República: Pierre Puvis de Chavannes (1824-1898). Como já assinalou Vaisse, à maestria do desenho ele acrescentava ai nda a utilização de uma pal eta cromaticamente rica, que incorporava a luminosidade e o efeito atmosférico concebido pelos impressionistas. Além disso, recuperara um gênero há muito em desuso - o muralismo -, que se adaptava perfeitamente às demandas políticas do momento: 0 governo compreendia as pinturas como discursos visuais com funções claramente pedagógicas, destinadas à educação das massas, e, nesse sentido, a pintura mural era a saída perfeita. Com isso, Puvis tornou-se uma espécie de pintor oficial do regime, recebendo diversas encomendas de grande vulto, como as incumbências de decorar o Panthéon, as paredes da Sorbonnee as do H ôtel de Ville.

Em sua figuração, mais uma vez 0 artista obtinha combinações visuais que agradavam a muitos. Por um lado, aos partidários da tradição acadê mica, por executar pinturas cujo teor, caráter e tamanho se adequavam ao gênero histórico; de outro lado, também a elite política da época se encantava com a renovação das figurações por ele criadas; sua interpretação de Saint $\mathrm{G}$ eneviève como uma mártir de origem popular, cujo patriotismo era sincero e comovente, sem ser necessariamente bélico, era com muita probabilidade a encarnação mais perfeita das virtudes aspiradas pelo novo regime. E, por fim, seu cromatismo vivo e suave demonstrava um diálogo com as vanguardas, contribuindo para que fosse elevado à condição de pintor oficial, sem ser visto como um "passadista", ou seja, mais um típico artista pompier dedicado a acrescentar inovações, muitas vezes artificiais e anedóticas, ao grande gênero (cf. Vaisse, 1995, pp. 231-247).

U m de seus admiradores foi o pintor brasileiro Belmiro de Almeida, que entre 1896 e 1899 foi aluno da A cadémiejulian, embora já fosse artista renomado nos círculos locais. Comentando a exposição geral de belas-artes de 1884, o crítico de arte Gonzaga-D uque o apontou como uma das mais vigorosas forças de renovação da pintura nacional, em especial por sua tela 


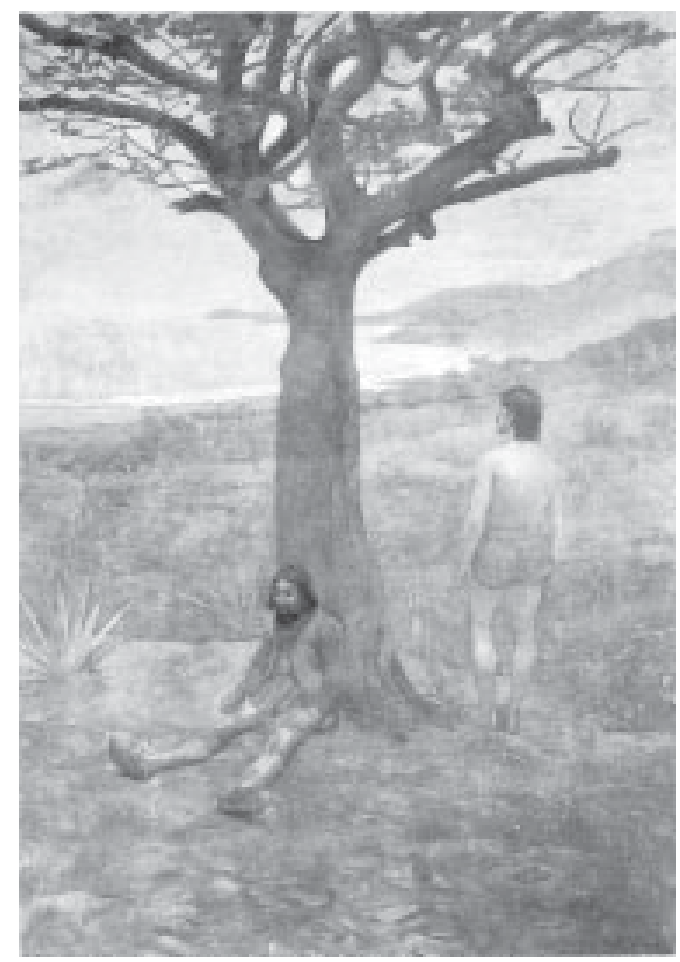

Belmiro de Almeida, Os descobridores, 1899.

Museu Histórico do Itamaraty.

Arrufos, dedicada a uma rusga conjugal. Como disse o crítico, "Belmiro éo primeiro, pois, a romper com os precedentes, é o inovador; é o que compreendendo por uma maneira clara a arte do seu tempo, interpreta um assunto novo" (G onzaga-D uque, 1995, p. 212).

A renovação temática efetuada pelo pintor, vista por G onzaga-D uque como o verdadeiro caminho que a artenacional deveria seguir, tinha, certamente, inspirações no além-mar. Sua tela 0 s descobridores estabelece um diálogo perceptível com a tela Le pauvre pêcheur de Puvis de Chavannes. Formalmente há grande afinidade entre as figuras representadas, como na conotação popular das personagens; 0 cromatismo também é muito similar, com opção por tons terrosos e por um certo embranquecimento espesso da pal eta. M esmo na composição há pontos de convergência: em ambas o horizonteé cortado por uma linha, quase abstrata, que caracteriza o mar ehá uma presença comum de grandes espaços vazios na tela, que também revelam uma propensão para a geometrização e para a escal a das obras murais.

0 fato de Belmiro ter procurado inspiração em um artista como Puvis de Chavannes é algo importante para que pensemos o que tal geração de 


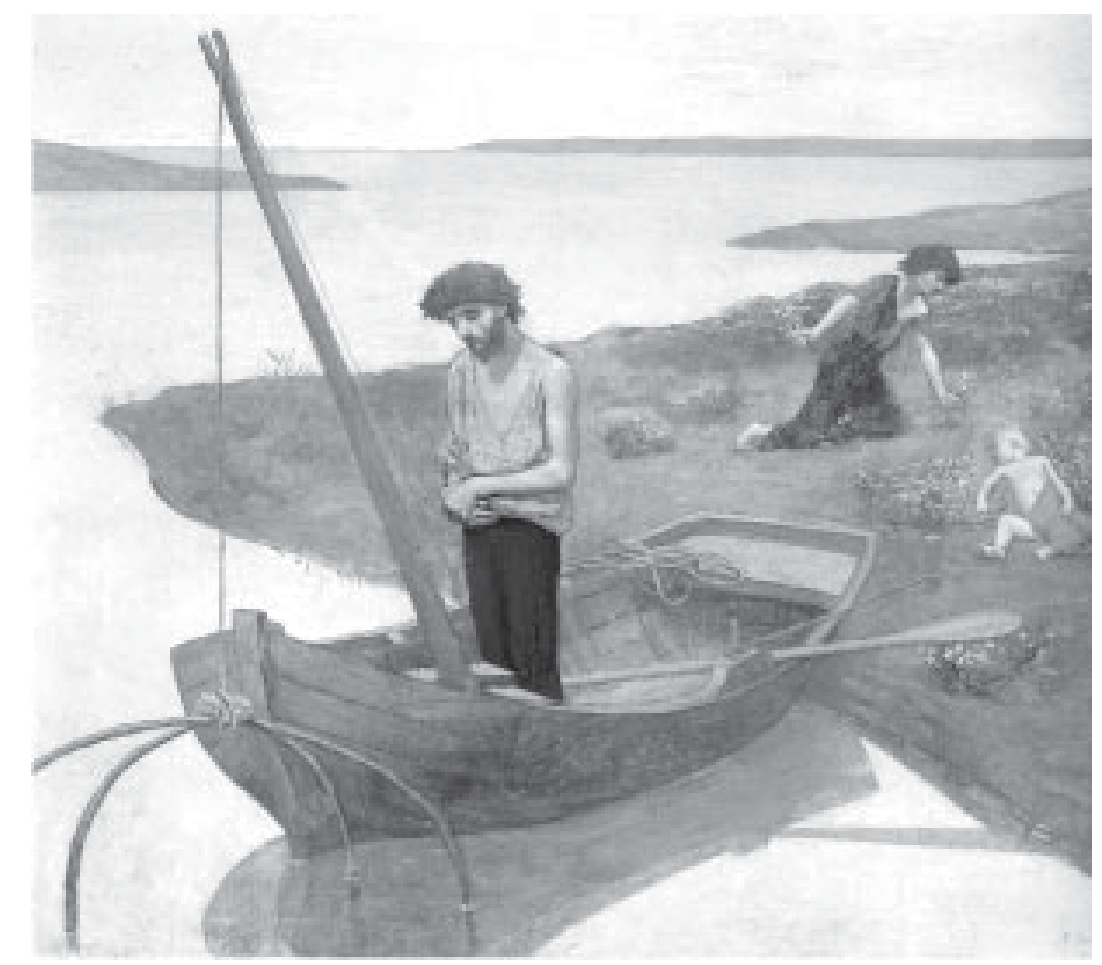

Pierre Puvis de Chavannes, Le pauvre pêcheur, 1881. Museu D’Orsay.

artistas entendia por "arte moderna". H á vários quadros produzidos entre finais do século XIX e inícios do XX, classificados até hoje como "acadê micos", que foram inspirados em obras vistas, à época, como "modernas". Entre esses pintores pode-se citar Rodolfo Amoedo, cuja paleta sensual e luminosa evidencia um conhecimento notável das descobertas dos grupos de vanguarda (cf. M igliaccio, 2001). U ma de suas aquarelas, Cena de café, possui afinidades notáveis com 0 Absyntho, de D egas, demonstrando perfeito conhecimento e incorporação da temática e da fatura impressionistas (ver p. 358). Há outros casos dignos de nota, como o retrato do pintor Arthur Timótheo da Costa, pintado por C hambelland, que foi claramente inspirado na estrutura formal desenvolvida por W histler em Arranjo em branco e negro ou A mãe do artista (ver p. 359).

Essas alusões explícitas às obras de artistas franceses não devem ser tomadas como meras cópias. A referência a outras obras era um aspecto de sejável da prova de erudição. M as é correto afirmar que havia, também, originalidade. Afinal, os artistas selecionavam os modelos a serem seguidos e os adaptavam aos seus próprios programas estéticos. Como bem assinalou Jorge Coli, 


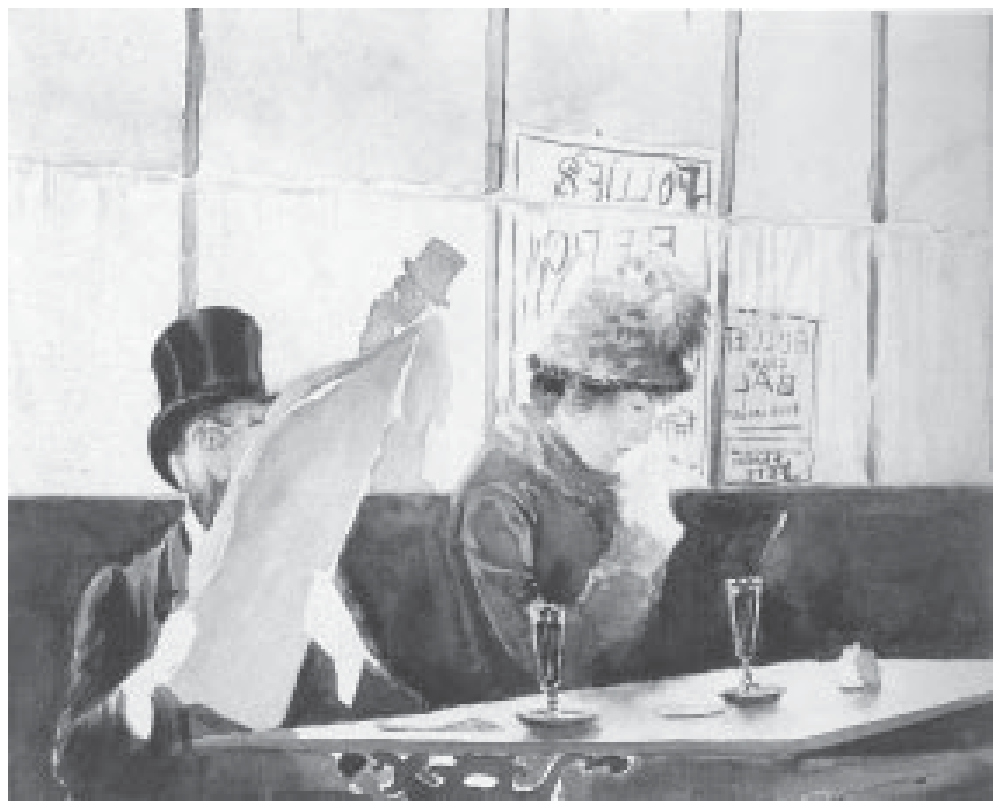

Rodolfo Amoedo, Cena de café. MASP.

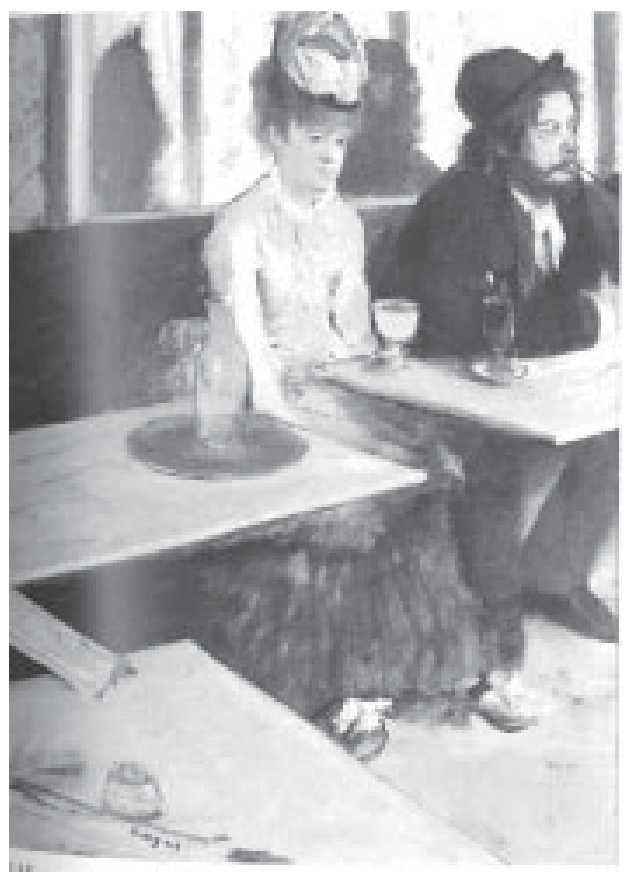

Edgar Degas, Dentro de um café ou 0 absyntho, 1876. Museu D'Orsay. 


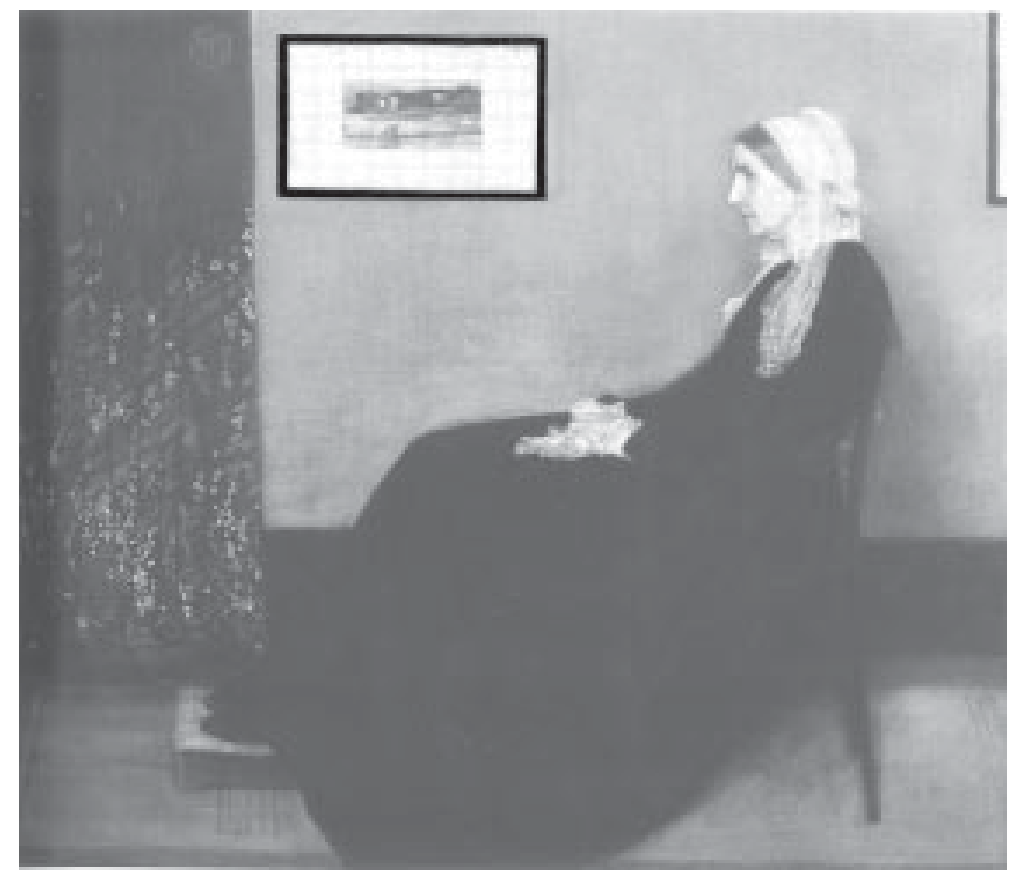

James Abbott McNeill Whistler, Arranjo em branco e negro ou A mãe do artista, 1871. Museu D'Orsay.

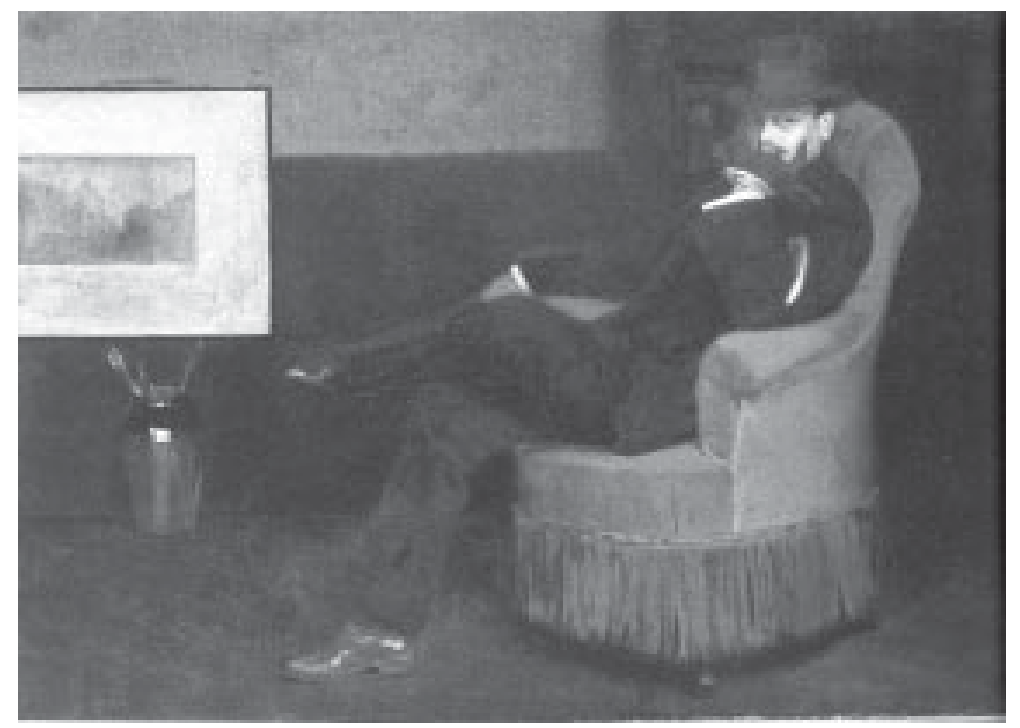

Carlos Chambelland, Retrato de A. Timótheo da Costa, 1909. MASP. 
[...] a inovação, a especificidade do fazer não eram tidos então como valores tão fundamentais como para o público de hoje. 0 que importava era dar conta de um programa ambicioso: menos contava a novidade intelectual, do que a felicidadeem vencer os escolhos inerentes ao projeto. N esse contexto, a citação e a referência ao passado não são, de modo nenhum, pastiches originados pela falta de imaginação, mas um modo de mostrar como aquele momento preexistente ressurge numa outra inter-relação (1997, p. 9).

Alguns artistas dessa geração al mejavam, ao mesmo tempo, assimilar os legados que Ihes eram exigidos pelos mestres acadêmicos franceses e brasileiros, para os quais, vale lembrar, deveriam mostrar que o estágio em Paris revelara-se frutífero; mas também incorporaram, ainda que de forma matizada, as inovações artísticas que testemunharam na cidade. A essa síntese formal se somava ainda uma terceira e difícil exigência: como artistas cosmopolitas oriundos de nações periféricas, se viam na tortuosa tarefa de realizar uma arte que causasse impacto na terra natal, ou seja, uma arte que fosse, de algum modo, nacional, mas segundo parâmetros de julgamento apreendidos no exterior, ou seja, internacionais.

N esse sentido, a busca por uma arte brasileira passava, necessariamente, por uma sintonia com os modelos europeus que deveriam ser plenamente conhecidos, habilmente absorvidos e originalmente recriados. A passagem por Paris era, pois, uma etapa absolutamente indispen sável para o conhecimento dos modelos de "bem fazer" arte, efornecia o momento privilegiado de contato com aquele "moderno" que, posteriormente, seria interpretado segundo os condicionantes locais. 0 caso da pintura de Belmiro é, novamente, exemplar.

0 artista inspirou-se nas obras realizadas por Puvis de Chavannes, um pintor que era identificado como a síntese perfeita entre duas escolas antípodas (a acadêmica e a impressionista) e que, ademais, havia consolidado a representação iconográfica emblemática do regime republicano. Como já foi dito, Belmiro de Almeida utilizava na tela os mesmos recursos formais do mestre francês, mostrando assim conhecer a tradição acadêmica, ao mesmo tempo que trazia os elementos suficientes para que continuasse a ser identificado como um "inovador". M as a própria iconografia utilizada faz emergir um outro elemento, a meu ver fundamental, para a compreensão da pintura como algo moderno.

$\mathrm{N}$ a tela (p. 312) estão figurados dois homens perdidos em meio a uma natureza exuberante e selvagem. Trata-se de dois náufragos que desembar- 
caram em terras novas, desconhecidas até então pela civilização européia. Esse momento nada tem de glorioso. É desse abandono original, que leva as figuras masculinas - aliás pouco heróicas - ao desespero e ao desalento, que nasce o nosso país, o Brasil. N esse pessimismo subjacente à tela pode se perceber um diálogo, mordaz, com a tradição da pintura de história local. Belmiro recusou-se a representar o descobrimento como um ato fundador digno de celebração, recusou-se também a enaltecer a natureza tropical, como tantos artistas imperiais haviam feito antes dele. 0 pintor re presentou o "marco inaugural" da nação como um momento de abandono, involuntário, de dois homens fragilizados, desprotegidos diante de uma natureza assustadora. E ao fazêlo traduziu um espírito crítico com relação à tradição artística anterior. Para ele, o destino do artista moderno estava nessa postura: ele deveria romper com uma perspectiva idealista e oficial da arte produzida durante 0 Império, trazendo novos temas, novas interpretações, agora mais livres e críticas, por intermédio de faturas que mostrassem diálogo com as novas correntes parisienses.

A Académie Julian, ainda pouco reconhecida como escola de formação de nossos artistas, desempenhou papéis centrais: promoveu a educação das artistas mulheres, preparou os jovens para os difíceis concursos de admissão na EBA e engendrou ainda determinados paradigmas artísticos junto aos seus discípulos. Paradigmas que incorporavam, ainda que de modo enviesado e segundo um prisma hoje visto como conservador, as novidades estéticas que perpassavam o campo artístico francês. 0 sentido que 0 termo moderno adquiriu para aquela geração que cursou seus ateliês, para ser corretamente desvendado, passa por identificar as múltiplas e comple xas relações de inspiração, tradução e reinterpretação de model os artísticos que por ali circulavam e que foram particularmente acessados por cada um desses muitos artistas nacionais que para lá se dirigiram, vários dos quais ainda pouco conhecidos e estudados. 


\begin{tabular}{|c|c|c|}
\hline ARTISTAS & ANOS DE PASSAGEM & PROFESSORES \\
\hline Alexandre de $C$ aldas & $1888-1890$ & Laurens/C onstant \\
\hline Alexandre Pereira & 1899 & Laurens/C onstant \\
\hline Angels Santos M oreira & 1898-1899 & Lefèbvre/Fleury \\
\hline Antonio Baptista & 1906-1907 & Lefèbvre/Fleury \\
\hline Antonio Lopez Pereira & 1900 & Lefèbvre/Fleury \\
\hline Antonio M achado & 1891-1892 & Laurens/C onstant \\
\hline Araripe M acedo & 1901 & Laurens \\
\hline Auguste Bracet & $1912-1913$ & Ateliês reunidos/Baschet/G ervais \\
\hline Auguste Petit & 1892 & Brantot/D oucet \\
\hline Baungartner & 1891-1892 & Laurens/C onstant \\
\hline Belmiro de Almeida & 1896-1899 & Lefèbvre/Fleury \\
\hline Benedito Calixto & 1883-1884 & \\
\hline Campos Ayres & $1909-1910$ & Ateliêsreunidos/Laurens \\
\hline Carlos D 'Azevedo & 1891-1892; 1898-1900 & D oucet/Baschet/Schommer \\
\hline Conceição Silva & 1894-1895 & Laurens/C onstant \\
\hline Corbiliano da Villaça & 1897-1898 & Lefèbvre/Fleury \\
\hline DaCosta & 1887-1889 & \\
\hline D akir Parreiras & 1908-1910 & Ateliês reunidos \\
\hline D ario Barbosa & $1902-1906$ & Laurens/Lefèbvre/Fleury \\
\hline Durval & 1892 & Laurens/C onstant \\
\hline Eduardo de Sá & $1888-1890$ & \\
\hline Eliseu Visconti & 1893-1897; 1904; 1916 & Laurens; Baschet/Schommer \\
\hline Engellons & 1894-1895 & \\
\hline Ezequiel Pereira & 1894-1895 & Laurens/C onstant \\
\hline Fernandez Patto & 1894 & \\
\hline Fernando de Carvalho & $1890-1891$ & Laurens/C onstant \\
\hline Fernando $\mathrm{M}$ achado & 1897 & Lefèbvre/Fleury \\
\hline Floriano Peixoto & 1894 & Laurens/C onstant \\
\hline Fonseca da C osta & 1896-1897 & \\
\hline Frederico de $M$ artini & 1890 & Laurens/C onstant \\
\hline Frederico Ramos & 1889-1894 & Laurens/Constant \\
\hline H élios Seelinger & 1904 & Laurens \\
\hline H enrique Alvim Correa & 1893 & \\
\hline H enrique Bernardelli & 1893 & Bouguereau \\
\hline $\mathrm{H}$ enrique $\mathrm{C}$ aval heiro & 1919 & \\
\hline H enrique Costa & $1912-1913$ & Ateliês reunidos - escultura \\
\hline Ismael N ery & 1920 & \\
\hline J. B. de Lima & $1894-1896$ & Laurens/C onstant \\
\hline
\end{tabular}




\begin{tabular}{|c|c|c|}
\hline ARTISTAS & ANOS DE PASSAGEM & PROFESSORES \\
\hline João Batista da C osta & $1890-1897$ & Lefèbvre/Fleury \\
\hline José Archimedes & 1897-1901 & Lefèbvre/Fleury \\
\hline José Cruz & 1895 & Lefébvre/Fleury \\
\hline José de Andrada & 1911-1912 & Ateliês reunidos/Laurens \\
\hline José de Brito & 1890; 1894 & Laurens/C onstant \\
\hline José M arques C ampão & 1910-1912 & Ateliês reunidos/Laurens \\
\hline José Rodrigues & $1910-1911$ & Ateliês reunidos/Laurens \\
\hline Kanto & 1921 & Ateliês reunidos/Baschet \\
\hline Lucílio Albuquerque & 1906-1910 & Royer/Laurens \\
\hline Luiz Teixeira de Barros & 1911 & Lefèbvre/Fleury \\
\hline Lummart & 1913 & Laurens \\
\hline M adruga Filho & 1895-1898 & Baschet/Schommer \\
\hline M anuel da Rocha & 1900 & Laurens/C onstant \\
\hline M anuel Pereira Rocha & 1900 & Laurens/C onstant \\
\hline M ario Barbosa & $1902-1906 ; 1909-1910$ & Laurens/Lefèbvre/Fleury \\
\hline M edeiros & 1894 & \\
\hline M r. de Porto Seguro & 1890 & Laurens/C onstant \\
\hline $\mathrm{N}$ elson $\mathrm{N}$ etto & 1920 & Ateliês reunidos \\
\hline Pedro de Castillo & 1889 & \\
\hline Peixoto & 1890-1894 & Laurens/C onstant \\
\hline Presciliano Silva & 1905-1907 & Lefèbvre/Fleury \\
\hline Raul de Sá & 1911-1912 & Ateliês reunidos - escultura \\
\hline Reighantz & 1900 & Lefèbvre/Fleury \\
\hline René Pinheiro & $1918-1920$ & Ateliês reunidos \\
\hline Roberto Colin & 1906-1908 & Royer/Laurens \\
\hline Roberto M endez & 1891-1892 & Laurens/C onstant; Brantot/D oucet \\
\hline Robespierre de Farias & 1910 & Lefèbvre/Fleury \\
\hline Rodolfo Chambelland & 1906 & Royer/Laurens \\
\hline Rodrigues Lopes & 1892-1893 & \\
\hline Sá de Franco & 1874 & \\
\hline Souza Bizenda & 1888 & \\
\hline Souza Pino & 1892; 1894 & Laurens/C onstant \\
\hline Teodoro Braga & $1900-1905$ & Laurens/C onstant; Royer \\
\hline Tulio M uganani & 1914 & \\
\hline Valle Jr. & $1906-1910$ & Royer/Laurens; Ateliês reunidos/Laurens \\
\hline Vicente do Rego M onteiro & 1911-1914 & Ateliês reunidos - escultura \\
\hline Weingartner & $1882-1884$ & \\
\hline
\end{tabular}

D ados obtidos nos Archives N ationales de Paris, microfilmes série 63AS1 a 63AS9. 


\section{Referências Bibliográficas}

Alves, C aleb Faria. (2003), Benedito Calixto ea construção do imaginário republicano. Bauru, Edusc.

BASH KIRTSEFF, M arie. (1925), Journal. Paris, Bibliothèque Charpentier.

Bourdieu, Pierre. (1989), "A institucionalização da anomia". In: O poder simbólico. Lisboa, Difel.

Callen, Anthea. (1997), "The body and difference: anatomy training at the École des Beaux-Arts in Paris in the later ninetheenth century". Art H istory. L ondon, 1 (20), mar.

C oLI, Jorge. (1997), A Batalha de Guararapes de Victor M eirelles e suas relações com a pintura internacional. C ampinas. Tese de Livre-D ocência. IFCH , U nicamp.

C OstA, Laura M alosetti. (2001), Los primeros modernos: arte y sociedad en Buenos Aires a fines del siglo XIX. Buenos Aires, Fondo de Cultura Económica de Argentina.

D URAND, José C arlos. (1989), Arte, privilégio e distinção. Artes plásticas, arquitetura e dasse dirigente no Brasil, 1855/1985. São Paulo, Perspectiva/Edusp.

Feher, Catherine. (1994), "Women at the Académie Julian in Paris". The Burlington M agazine. London, 1100 (CXXXVI).

Fried lander, Walter. (2001), De D avid a D elacroix. São Paulo, Cosac \& N aify.

$G_{\text {ARB, }}$ Thamar. (1998), Sisters of the B rush: womenśs artistic culture in late nineteenthcentury Paris. N ew H aven/London, Yale U niversity Press.

G oLd STEIN , C arl. (1996), Teaching academy: academies and schoolsfrom Vasari to Albers. Cambridge, Cambridge University Press.

Gonzaga-Duque Estrada, Luís. (1995), A arte brasileira. Campinas, Mercado de Letras (introdução e notas de Tadeu Chiarelli).

G Run CHEC, Philippe. (1990), "Les Éleves americains, peintres et sculpteurs, a l'École des BeauX-Arts dans la deuxième moitie du XIX ème siècle. In: Le Voyage de Paris. Paris, Reunión des M usées $N$ ationaux.

LANDES, Joan. (1988), Women and the public sphere in the age of French Revolution. N ew York, Cornell University Press.

LEPDOR, Catherine. (2001), Louise Breslau: de l'impressionnisme aux années folles. Lausanne, M usée C antonal des Beaux-Arts de Lausanne.

Le Voyage de Paris. Les Americans dans les Écoles d'Art, 1868-1918. (1990), Paris, Reunión des M usées $\mathrm{N}$ ationaux.

M ICELI, Sergio. (1995), N acional estrangeiro: história social e cultural do modernismo artístico em São Paulo. São Paulo, Cia. das Letras.

M Igliaccio, Luciano. (2000), 0 século XIX. C atálogo da mostra do Redescobrimento. São Paulo, Associação Brasil 500. 
. (2001), "Rodolfo Amoedo, o mestre, deveríamos acrescentar". In: 30 mestres da pintura no Brasil. 30 anos Credicard. São Paulo, M ASP.

N OCH LIN , Linda. (1971), “W hy there been no great women artists?”. In: H ESS, T homas

\& BAKER, Elizabeth (eds.). Art and sexual politics. N ew York, M acmillan.

N o EL, D enise. (1988), Academie Julian: les ateliers pour dames, 1868-1907. M emoire de matrise. UER D'art et d'Archeologie. Université de Paris 1, Sorbonne. . (1997), Les Femmes peintres au Salon. Paris, 1863-1889. Paris. Thèse de D octorat sous la D irection de M ichelle Perrot. Université de Paris 7.

O HASH I, H elena Pereira da Silva. (1969), M inha vida. São Paulo, s.e.

SAUER, M arina. (1990), L'Entrée des femmes à l'École des BeauX-Arts, 1880-1923. Paris, ESNBA.

SH ERIFF, M ary. (1996), The exceptional women: Elisabeth Vigée Lebrun and the cultural politics of art. C hicago/London, University of C hicago Press.

SIM IONı, Ana Paula C avalcanti. (2004), Profi ssão artista: pintoras eescultoras brasilei ras entre 1884 e 1922. São Paulo. Tese de D outorado. D epartamento de Sociologia, Faculdade de Filosofia, Letras e Ciências H umanas de U niversidade de São Paulo.

TarasantchI, Ruth Sprung. (1996), Os Worms. Bertha e Gasão. São Paulo, Pinacoteca do Estado de São Paulo.

V AISSE, Pierre. (1995), La Troisième Republique et les peintres. recherches sur les rapports des pouvoir publics et de la peinture en France de 1870 a 1914. Paris, Flammarion.

W EISBERG, Gabriel \& BECKER, Jane. (2000), 0 vercoming all obstacles the women of the Académie Julian. N ew York, The D ahesh M useum, Rutgers University Press. 


\section{Resumo}

A viagem a Paris de artistas brasileiros no final do século XIX

Esteartigo propõe-sea analisar o papel da Académie Julian, uma academia privada que recebeu grande parte dos artistas brasileiros que aportaram em Paris entre o final do século XIX e o início do século XX. Três temas são aqui abordados: a formação recebida; a importância da instituição para as artistas do sexo feminino e o modo como as novidades estéticas que despontavam em Paris foram absorvidas e reinterpretadas pelos artistas patrícios que para lá se dirigiram.

Palavras-chave: Arte; Academia; Educação; M ulher; M odelos franceses.

\section{Abstract}

The trip to Paris by Brazilian artists of the 19th century

This paper analyzes the roletheAcadémie Julian, a private academy, played as it received a great part of artists who went to Paris between the end of the 19th and the beginning of the 20th century. T hree themes are discussed: what they studied, the importance of the institution for the female artists and how esthetic novelties that were cropping up in Paris at the time were absorbed and reinterpreted by those artists. Keywords: Art; Academia; Education; Women; French models.

Texto recebido em 18/ $11 / 2004$ e aprovado em 4/1/2005.

Ana Paula Cavalcanti Simioni é doutora em Sociologia (USP) e professoradaEscola deArte, CiênciaseH umanidades (EACH) da USP. É autora de Di Cavalcanti ilustrador: trajetória de um jovem artisa gráfico na imprensa (19141922). E-mail: anapcs @usp.br. 